\section{Residência médica: estresse e crescimento}

Martins, Luiz Antonio Nogueira. São Paulo: Editora Casa do Psicólogo; 201 páginas. ISBM 85-7396-436-7

Para escrever um bom texto e, assim, tornar-se um escritor, saltando de aspirante a profissional, é necessário ler. E não seria exagero dizer: ler muito. E, os escritores médicos, quando escrevem sobre suas especialidades, precisam mostrar que receberam esse estímulo vigoroso da leitura. Quando esse estímulo vem aliado à prática profissional especializada, o resultado é surpreendente. Esse é o caso do livro de Luiz Antonio Nogueira Martins, psiquiatra e professor da Universidade Federal de São Paulo (UNIFESP). Em seu livro, ele nos brinda com a combinação e análise de três temas candentes em Medicina: as vicissitudes da formação médi$\mathrm{ca}$, o estresse profissional experimentado pelos médicos em serviço e as oportunidades de crescimento emocional e profissional do médico daí decorrentes.

O professor Luiz Antonio é conhecido no meio psiquiátrico brasileiro como um dos pioneiros, em meados da década de 1970, na introdução do trabalho com interconsulta psiquiátrica no Hospital Geral, enquanto supervisor do Serviço de Interconsulta em Saúde Mental do Hospital São Paulo, da Escola Paulista de Medicina, São Paulo. Esse pioneirismo foi estendido, mais tarde, em sua coordenação do Núcleo de Assistência e Pesquisa em Residência Médica.

É a partir dessas experiências pessoais e profissionais, adquiridas ao longo de três décadas, que seu livro Residência médica: estresse e crescimento vem à luz hoje para ajudar a captar essas vozes médicas que fluem, desde tempos imemoriais, e que continuarão fluindo dentro do hospital. Um vozerio que sempre precisará ser compreendido e analisado.

O livro, com seis capítulos fundamentados na literatura científica, apresenta três características fundamentais: é recomendado pelo presidente da Associação Brasileira de Educação Médica; seus quatro capítulos podem ser lidos em uma tarde; e é uma referência, atualizada e segura, para a temática do estresse que atinge, universalmente, médicos no hospital geral. Portanto, serve para consulta tanto para aquele médico que possui anos de prática, como para o médico residente que começa a dar seus primeiros passos na especialidade de escolha.

O capítulo I atribui uma origem acadêmica à Residência Médica, em 1889, de autoria do médico cirurgião Dr. William Halsted, nos EUA, o qual, já na época, manifestava problemas que acompanhavam e ainda acompanham a educação e o trabalho médico até os dias atuais. A legislação brasileira sobre Residência é apresentada. As questões conflitantes provocadas pela dualidade de funções do residente como médico e aprendiz são analisadas em suas conseqüências para o estresse e aprendizado.

O capítulo II é um primor de síntese teórica e de esclarecimentos e recomendações sobre o estresse psicológico inerente à tarefa médica. Nesse capítulo, temos o conceito do estresse, desde suas origens na Física, até seu entendimento ao ser expresso no trabaIho médico. A grande questão de como chegar tão perto do paciente para compreendê-lo sem o médico, no entanto, estressar-se além da conta e adoecer, é o mote do capítulo.

\section{RESIDÊNCIA MÉDICA}

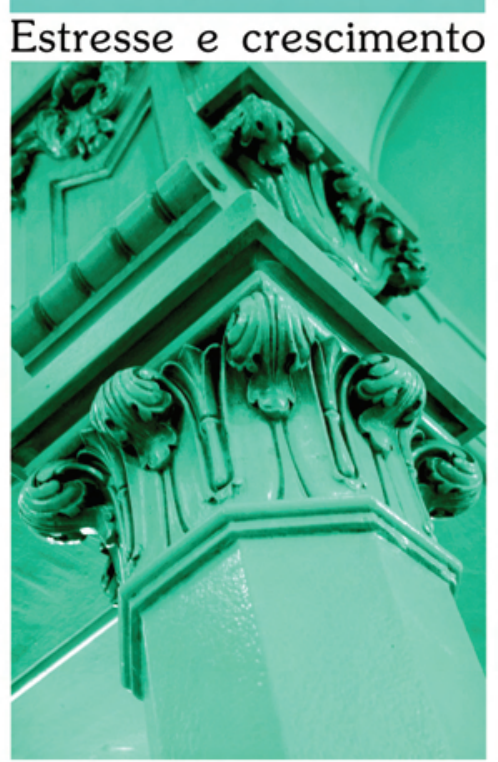

Luiz Antonio Nogueira Martins

Casa do Psicólogo@

O capítulo III aborda o estresse na Residência Médica com rigor didático e apresentação de literatura pertinente. Descreve o estresse em três categorias: profissional, situacional e pessoal.

Os capítulos IV e V constituem o ponto forte do livro, pois contêm pesquisas e procedimentos originais, orientados pelo autor, que mostram dados oriundos de médicos residentes do Hospital São Paulo. O nível de estresse diminui à medida que o treinamento se desenvolve. Como pesquisa qualitativa, os médicos têm voz e assim têm um espaço de desabafo, enquanto aprendem a serem especialistas.

O capítulo VI fecha o livro com o Núcleo de Assistência e Pesquisa em Residência Médica (NAPREME) voltado para a saúde do médico, o qual poderia servir de referência para outros programas brasileiros de residência médica. Enfim, os médicos não são perfeitos e, vez por outra, também precisam de cuidados. A literatura brasileira especializada passa a ter, neste livro, uma síntese do estado da arte no tema da "Residência médica: estresse e crescimento".

\section{Ibiracy de Barros Camargo}

Centro Universitário "Barão de Mauá", Ribeirão Preto (SP), Brasil

José Onildo B. Contel

Faculdade de Medicina de Ribeirão Preto (FMRP), Universidade de São Paulo (USP), Ribeirão Preto (SP), Brasil Hospital Dia Psiquiátrico, Hospital das Clínicas, Faculdade de Medicina de Ribeirão Preto (FMRP), Universidade de São Paulo (USP), Ribeirão Preto (SP), Brasil 